\title{
Equilibrium facilitated mass transfer in plate type reactive membrane separation devices
}

\author{
Lii-ping Leu and Yi-Xiong Qui \\ Department of Chemical Engineering, National Taiwan University, Taipei 10617, Taiwan \\ (Received 2 June $2005 \cdot$ accepted 21 November 2005)
}

\begin{abstract}
The introduction of mobile carrier species which react reversibly with the solute species in liquid membrane mass transfer separation devices can give enhanced mass transfer rate. For one-dimensional laminar boundary layer flow of a Newtonian fluid past a single-membrane separator with equilibrium facilitated transport inside the membrane, the mass transfer rate in the separator was analyzed numerically. For a Damköhler number equal to infinity, the effect of maximum facilitation factor, dimensionless equilibrium constant, dimensionless velocity and similarity transformation parameter on the performance of separators was investigated. The dependence of the membrane-fluid interfacial concentration and equilibrium facilitation factor on dimensionless velocity and similarity transformation parameter was discussed.
\end{abstract}

Key words: Facilitated Transport, Damköhler Number, Mass Transfer

\section{INTRODUCTION}

Laminar flow mass transfer in membrane devices is of considerable interest in the areas of dialysis, heavy-metal ion separation, gas separation and artificial oxygenation [Scott, 1980; Cussler, 1986]. The mass transfer rate attainable in membrane separation devices is often limited by solute transport through the membrane. The addition of mobile and reactive carrier species into the membrane, with which the solute reacts reversibly, is of interest because it can give increased mass transfer and high selectivity of the solute [Stroeve and Kim, 1987]. In this technique an organic liquid, immobilized in the pores of a microporous support, can be used to transfer a solute between two aqueous solutions. Supported liquid membranes offer an alternative method for the removal of organic pollutants from industrial waste streams [Noble and Way, 1987].

Schultz et al. [1974] analyzed the reactive membrane with Damköhler number approaching infinity and zero. Kim and Stroeve [1988] solved the case for fully developed laminar flow mass transfer in hollow fiber separation devices containing a reactive membrane when the Damköhler number for diffusion and reaction of the species inside the membrane approaches infinity, i.e., chemical reaction rates are much faster than diffusion rates [Kreuzer and Hoofd, 1987]. In many cases, the assumption of a rapid approach to equilibrium is far from valid [La force, 1966]. Leu and Strove [1993] solved the case for fully developed laminar flow mass transfer devices with nonequilibrium facilitated transport hollow fibers. Leu et al. [1996] calculated the mass transfer in parallel-plate separation devices with nonequilibrium facilitated reactive membranes. Ward [1970] studied the steady-state transport of nitric oxide through liquid membranes containing a ferrous chloride solution. He developed analytical solutions for steady-state nitric oxide flux under two limiting conditions, either reaction-equilibrium, diffusion-limited or reaction-limited transport.

To whom correspondence should be addressed.

E-mail: lleulii@ntu.edu.tw
In this study, we analyzed mass transfer in single-plate reactive membrane separator devices. The fluid to be treated flows in laminar flow past the single-membrane, and the equilibrium carrier-facilitated transport of the solute takes place inside the membrane. A second fluid bathes the outside of the single-membrane and removes the solute. The effects of the reaction and diffusion parameters of the solid-fluid-membrane system on solute separation are analyzed.

\section{THEORY}

A schematic diagram of the system is shown in Fig. 1. A Newtonian fluid with the solute to be extracted flows in one-dimensional, laminar boundary layer flow past a flat plate type membrane separator. The extractive single-plate membrane begins at $\mathrm{x}=0$. Just at this point the concentration of the solute is uniform and equal to $\mathrm{C}_{A i}$. The solute diffuses through the membrane by carrier-facilitated transport and then emerges into the second fluid, or dialysate, which bathes the outside of the membrane. The solute concentration in the dialysate is assumed to be negligible at all axial positions in the mass exchanger.

In this study, a reversible equilibrium reaction of the following form

$$
\mathrm{A}+\mathrm{B} \underset{k_{2}}{\stackrel{k_{1}}{\longrightarrow}} \mathrm{C}
$$

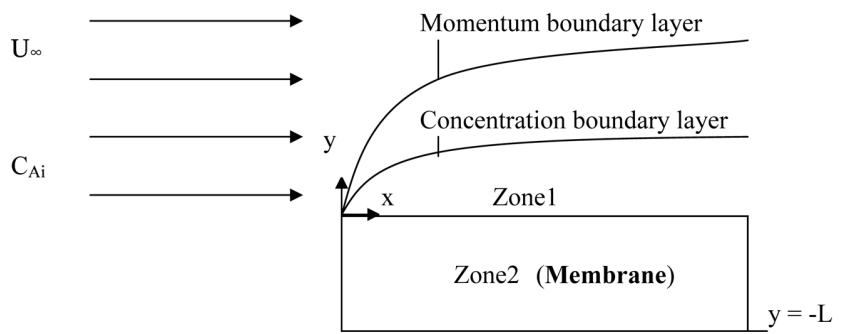

Fig. 1. Cross-section of the mass transfer separator with reactivemembrane. 
takes place inside the membrane with the kinetics suggested by the stoichiometry (elementary reaction). Here A is the solute, $\mathrm{B}$ is the carrier, and $\mathrm{C}$ is the carrier-solute complex species.

The theoretical analysis starts with the governing mass conservation equation for the solute species and the associated boundary conditions. Axial diffusion is neglected compared to axial convection. This assumption is a standard one for this type of problem [Schneider, 1957] and is valid when the Peclet number is greater than one hundred. For flat plate type membrane separation devices with constant free stream velocity, the pressure gradient is zero [Schlichting and Gersten, 2000]. With steady state assumption the governing equation and boundary conditions are given by

$$
\begin{aligned}
& \frac{\partial \mathrm{u}_{x}}{\partial \mathrm{x}}+\frac{\partial \mathrm{u}_{y}}{\partial \mathrm{y}}=0 \\
& \mathrm{u}_{x} \frac{\partial \mathrm{u}_{x}}{\partial \mathrm{x}}+\mathrm{u}_{y} \frac{\partial \mathrm{u}_{x}}{\partial \mathrm{y}}=v \frac{\partial^{2} \mathrm{u}_{x}}{\partial \mathrm{y}^{2}} \\
& \mathrm{u}_{x} \frac{\partial \mathrm{C}_{A 1}}{\partial \mathrm{x}}+\mathrm{u}_{y} \frac{\partial \mathrm{C}_{A 1}}{\partial \mathrm{y}}=\mathrm{D}_{A} \frac{\partial^{2} \mathrm{C}_{A 1}}{\partial \mathrm{y}^{2}} \\
& \text { B.C. } 1 \mathrm{x}=0, \mathrm{u}_{x}=\mathrm{U}_{\infty}, \mathrm{C}_{A 1}=\mathrm{C}_{A i} \\
& \text { B.C. } 2 \mathrm{y}=0, \mathrm{u}_{x}=0 \\
& \text { B.C. } 3 \mathrm{y}=0, \mathrm{u}_{y}=\mathrm{u}_{w} \\
& \text { B.C. } 4 \mathrm{y}=0, \mathrm{D}_{A} \frac{d C_{A 1}}{d \mathrm{y}}=\mathrm{k}_{w} \mathrm{H}\left(1+\mathrm{F}_{e q}\right) \mathrm{C}_{A 1} \\
& \text { B.C. } 5 \mathrm{y}=\infty, \mathrm{u}_{x}=\mathrm{U}_{\infty} \\
& \text { B.C. } 6 \mathrm{y}=\infty, \mathrm{C}_{A 1}=\mathrm{C}_{A i}
\end{aligned}
$$

Here $\mathrm{u}_{x}$ and $\mathrm{u}_{y}$ represent the velocities in $\mathrm{x}$ and $\mathrm{y}$ direction; $v$ is the kinematic viscosity; $\mathrm{C}_{A 1}$ is the solute concentration in zone $1 ; H$ is the equilibrium distribution coefficient; $\mathrm{D}_{A}$ is the diffusivity of the solute in zone $1 ; \mathrm{k}_{w}$ is the membrane mass transfer coefficient for the solute and $\mathrm{F}_{e q}$ is the equilibrium facilitation factor [Stroeve et al., 1976]. The fourth boundary condition imposes continuity of flux across the membrane-fluid interface. The right hand side of the equation accounts for facilitated transport, due to simple Fickian diffusion of the solute and reversible chemical reaction in the plate wall. The left hand side gives the species flux arriving at the wall from the lumen of the capillary [Noble, 1983]. The equilibrium facilitation factor for the reaction given by Eq. (1) can be expressed by

$$
\mathrm{F}_{e q}=\frac{\mathrm{D}_{B}^{\prime} \mathrm{C}_{T} \mathrm{~K}_{e q}}{\mathrm{D}_{A}^{\prime}\left(1+\mathrm{K}_{e q} \mathrm{HC}_{A 1}\right)}
$$

when the concentration at the downstream side of the membrane is zero [Stroeve et al., 1976]. The total carrier concentration in all forms (carrier and carrier-solute complex species) is given by $\mathrm{C}_{T}$, and $\mathrm{D}_{B}^{\prime}$ is the diffusivity of the carrier or the carrier-complex species. The equilibrium constant for Eq. (1) is denoted by $\mathrm{K}_{e q}$ and it is the ratio of the forward rate constant, $\mathrm{k}_{1}$ to the backward rate constant, $\mathrm{k}_{2}$. The prime superscript denotes properties in the membrane. Eq. (11) makes the common assumption that the diffusivities of the carriersolute complex and the carrier species are equal. This is reasonable because in many carrier-facilitated systems the carrier species molecular weight is much larger than the solute species. In the case of unequal diffusivities, Eq. (11) is somewhat modified, but the dependency on $\mathrm{C}_{A 1}$ remains unchanged. Consequently, the results in this study are not affected by the assumption for the diffusivities, and the mass transfer results in terms of different numerical values for $\mathrm{F}_{e q}$ remain valid.

The following dimensionless variables are introduced

$$
\begin{aligned}
& \mathrm{f}=\left(\frac{\mu \mathrm{U}_{\infty} \mathrm{x}}{\rho}\right)^{\frac{-1}{2}} \psi, \quad \eta=\frac{\mathrm{y}}{2}\left(\frac{\mathrm{U}_{\infty}}{v \mathrm{x}}\right)^{\frac{1}{2}}, \mathrm{u}_{x}=\frac{\partial \psi}{\partial \mathrm{y}}, \mathrm{u}_{y}=-\frac{\partial \psi}{\partial \mathrm{x}} \\
& \mathrm{C}_{1}^{*}=\frac{\mathrm{C}_{A 1}}{\mathrm{C}_{A i}}, \mathrm{k}_{w}=\frac{\mathrm{D}_{A}^{\prime}}{\mathrm{L}}, \quad \alpha=\frac{\mathrm{D}_{B}^{\prime} \mathrm{C}_{T} \mathrm{~K}_{e q}}{\mathrm{D}_{A}^{\prime}}, \quad \beta=\mathrm{K}_{e q} \mathrm{HC}_{A i} \\
& \mathrm{St}_{m}=\frac{\mathrm{k}_{w}}{\mathrm{U}_{\infty}}, \mathrm{Sc}=\frac{v}{\mathrm{D}_{A}}, \quad \mathrm{Re}_{x}=\frac{\rho \mathrm{U}_{\infty} \mathrm{x}}{\mu}
\end{aligned}
$$

Eqs. (2)-(9) become the following simultaneous ordinary differential equations by the similarity transformation

$$
\begin{aligned}
& \mathrm{f}^{\prime \prime \prime}+\mathrm{ff}^{\prime \prime}=0 \\
& \mathrm{C}_{1}^{* \prime \prime}+\mathrm{ScfC}_{1}^{* \prime}=0 \\
& \text { B.C. } 1 \eta=0, \mathrm{f}^{\prime}=0 \\
& \text { B.C. } 2 \eta=0, \mathrm{f}=\frac{\mathrm{u}_{w}}{\mathrm{U}_{\infty}} \sqrt{\operatorname{Re}_{x}}=\mathrm{V}_{y}^{*} \\
& \text { B.C. } 3 \eta=0, \frac{\mathrm{dC}_{1}^{*}}{\mathrm{~d} \eta}=\frac{\mathrm{St}_{m} \mathrm{H}}{\mathrm{Sc}} \sqrt{\operatorname{Re}_{x}}\left(1+\frac{\alpha}{1+\beta \mathrm{C}_{1}^{*}}\right) \mathrm{C}_{1}^{*} \\
& \text { B.C. } 4 \eta=\infty, \mathrm{f}^{\prime}=1 \\
& \text { B.C. } 5 \eta=\infty, \mathrm{C}_{1}^{*}=1
\end{aligned}
$$

The parameters $\alpha, \beta,\left(\mathrm{u}_{w} / \mathrm{U}_{\infty}\right) \sqrt{\mathrm{Re}_{x}},\left(\mathrm{St}_{m} \mathrm{H} / \mathrm{Sc}\right) \sqrt{\mathrm{Re}_{x}}$ are the maximum facilitation factor, the dimensionless equilibrium constant, the dimensionless velocity and similarity transformation parameter. The terms $\left(\mathrm{u}_{w} / \mathrm{U}_{\infty}\right) \sqrt{\mathrm{Re}_{x}}$ and $\left(\mathrm{St}_{m} \mathrm{H} / \mathrm{Sc}\right) \sqrt{\mathrm{Re}_{x}}$ are constants, which is the necessary condition for the similarity transformation. It implies that the ratio $\mathrm{u}_{w} / \mathrm{U}_{\infty}=$ const $\sqrt{\mathrm{Re}_{x}}$ and $\mathrm{St}_{m} \mathrm{H} / \mathrm{Sc}=$ const $\sqrt{\mathrm{Re}_{x}}$ or that $\mathrm{u}_{w} / \mathrm{U}_{\infty}$ and $\mathrm{St}_{m} \mathrm{H} / \mathrm{Sc}$ are inversely proportional to $\sqrt{\mathrm{x}}$ [Hartnett and Eckert, 1957]. The equilibrium facilitation factor can be in the form as

$$
\mathrm{F}_{e q}=\frac{\alpha}{1+\beta \mathrm{C}_{1}^{*}}
$$

and the maximum value that $\mathrm{F}_{e q}$ can attain is equal to the value of $\alpha$.

The mixing cup concentration is defined as

$$
\mathrm{C}_{m}=\frac{\int_{0}^{\infty} \mathrm{u}_{x} \mathrm{C}_{A 1} \mathrm{dy}}{\int_{0}^{\infty} \mathrm{u}_{x} \mathrm{dy}}
$$

and it is in the dimensionless form as

$$
\mathrm{C}_{m}^{*}=\frac{\int_{0}^{\infty} \mathrm{f}^{\prime} \mathrm{C}_{1}^{*} \mathrm{~d} \eta}{\int_{0}^{\infty} \mathrm{f}^{\prime} \mathrm{d} \eta}
$$

Boundary condition (17) shows that the similarity transformation parameter for inert diffusion of the species $\mathrm{A}$ is augmented by a factor $\left(1+\mathrm{F}_{e q}\right)$ where the number one accounts for Fickian diffusion of the solute and $\mathrm{F}_{e q}$ accounts for carrier-facilitated diffusion. The maximum facilitation factor, the dimensionless equilibrium constant, dimensionless velocity and the similarity transformation param- 
eter are the important parameters that influence the mass transfer of the solute from the fluid side of the flat-plate to the dialysate side.

To our knowledge, an analytical solution to Eqs. (13)-(19) is not available. For this case, the equations are solved numerically with Gear's stiff algorithm.

\section{RESULTS AND DISCUSSION}

The behavior of mass transfer of solute from the fluid in a singleplate mass transfer device through the reactive membrane is complex due to the coupling nonlinear differential equations and associated boundary conditions at different phases. The concentration of solute and the equilibrium facilitation factor is influenced by the maximum facilitation factor, the dimensionless equilibrium constant, dimensionless velocity, and similarity transformation parameter at Damköhler number equal to infinite.

Fig. 2 shows the effects of the maximum facilitation factor $\alpha$ on the dimensionless mixing cup concentration of solute versus dimensionless similarity variable $\eta$. The mixing cup concentration of solute increases with the dimensionless similarity variable $\eta$ on the surface of the membranes. The dimensionless mixing cup concentration will approach a value of unity after the similarity variable $\eta$ becomes large regardless of the value of the maximum facilitation factor $\alpha$. At $\eta=0$, the larger the value $\alpha$ is, the lower the mixing cup concentration will be, that is, near the membrane surface, large $\alpha$ has strong facilitation effect.

Fig. 3 shows the effect of maximum facilitation factor $\alpha$ on equilibrium facilitation factor $\mathrm{F}_{e q}$ vs. dimensionless equilibrium constant $\beta$. The maximum facilitation factor determines the maximum dimensionless magnitude of rate of carrier-facilitated transport to pure Fickean transport of species A. The parameter can be maximized by a large carrier concentration and carrier diffusivity to make carrier facilitation in the membrane dominant. When the maximum facilitation factor $\alpha$ is small, the reaction effect in the membrane is small. If $\alpha$ is increased, i.e., dissolving more carrier in the membrane, the mass transfer of solute will be increased. The dimensionless equilibrium constant gives a measure of the strength of a complexation

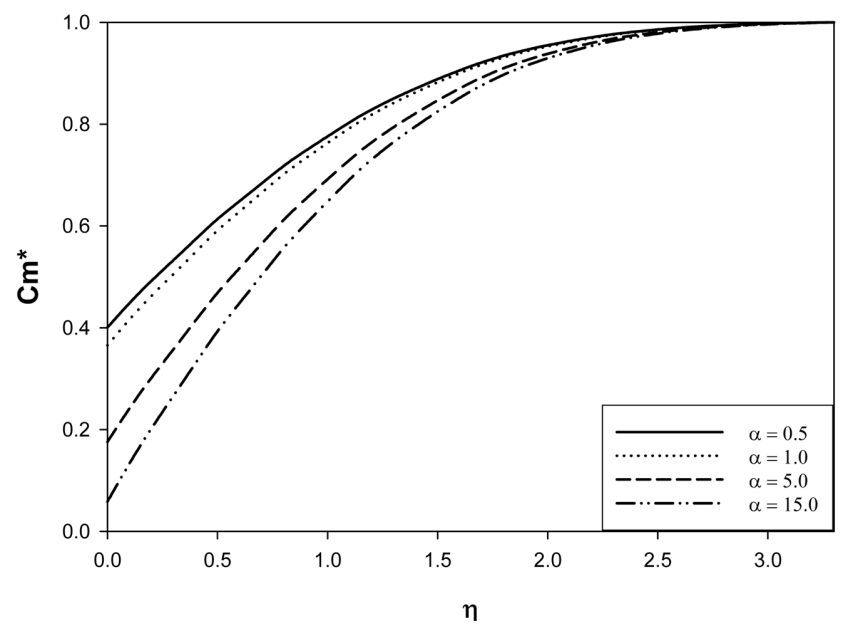

Fig. 2. The effect of the maximum facilitated factor on the mixing cup concentration of $A$ vs. the dimensionless similarity variable $\left(\beta=5.0, \mathrm{Sc}=1.0, \mathrm{Vy}^{*}=-0.4,\left(\mathrm{St}_{m} \mathrm{H} / \mathrm{Sc}\right) \sqrt{\operatorname{Re}_{x}}=1.0\right)$.

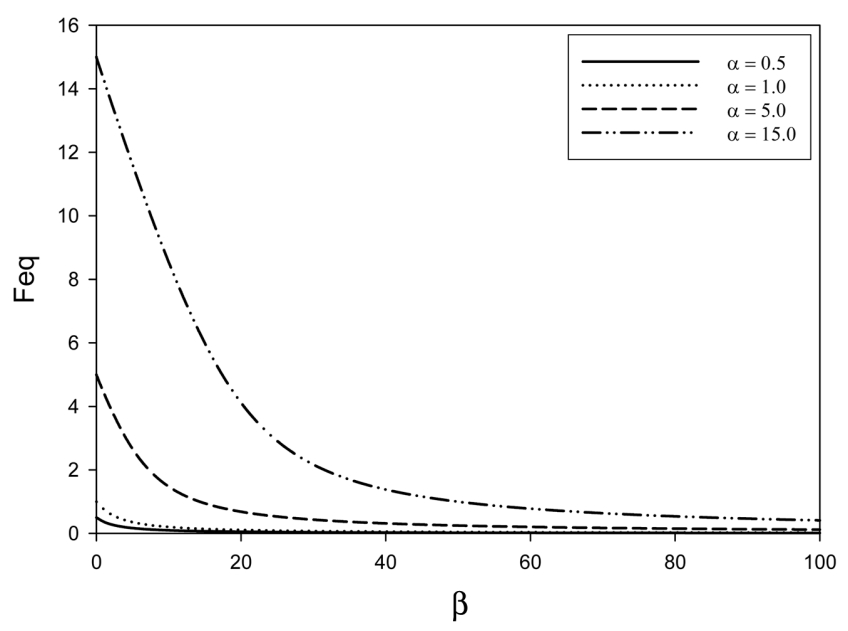

Fig. 3. The effect of the maximum facilitation factor on the equilibrium facilitation factor vs. the dimensionless equilibrium constant $\left(\mathrm{Sc}=1.0, \mathrm{Vy}^{*}=-0.4, \mathrm{St}_{m} \mathrm{H}\left(\mathrm{Re}_{x}^{1 / 2}\right) / \mathrm{Sc}=1.0\right)$.

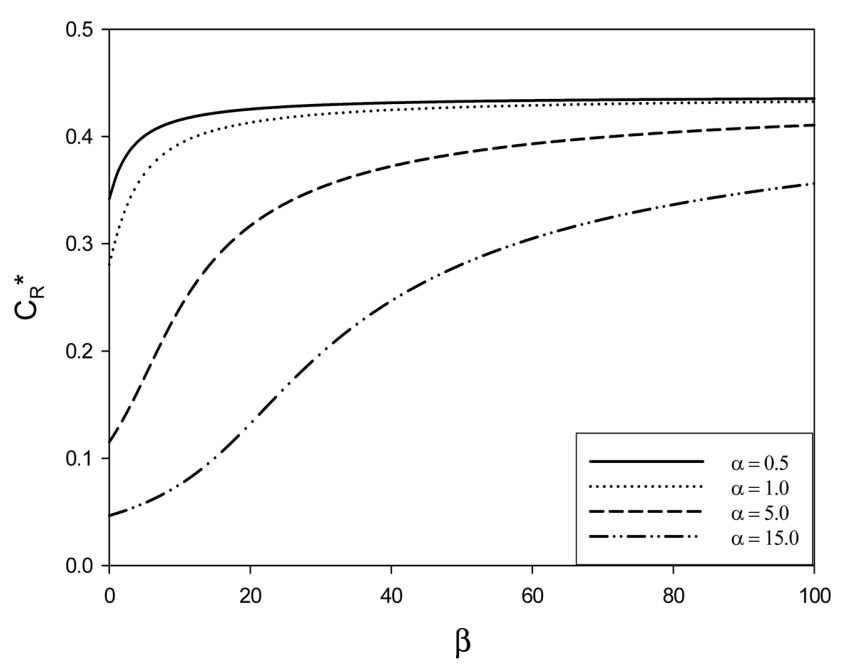

Fig. 4. The effect of the maximum facilitation factor on the dimensionless concentration of species $A$ at fluid-membrane interface vs. the dimensionless equilibrium constant $(\mathrm{Sc}=1.0$, $\left.\mathrm{Vy}^{*}=-0.4, \mathrm{St}_{m} \mathrm{H}\left(\mathrm{Re}_{x}^{1 / 2}\right) / \mathrm{Sc}=1.0\right)$.

reaction of the transport species with the carrier species. A higher value of the dimensionless equilibrium constant means either a larger value of equilibrium constant, equilibrium distribution coefficient, or inlet concentration. The decrease in mass transfer of solute is due to the saturation effect of the chemical reaction because of a large solute concentration on the fluid side.

Fig. 4 shows the effect of maximum facilitation factor $\alpha$ on the membrane-fluid interfacial concentration $\mathrm{C}_{R}^{*}$ vs. dimensionless equilibrium constant $\beta$. The higher the value of $\alpha$, the lower the membrane-fluid interfacial concentration will be. The maximum facilitation factor $\alpha$ represents the reaction in the membrane. When $\alpha=0$, no reaction takes place in the membrane. If $\alpha$ is increased, the mass transfer of solute will be increased by dissolving more carrier in the membrane. The carrier can greatly facilitate the diffusion of the solute from the interface. Then the interfacial concentration is decreased. When $\beta$ is large, the reaction is saturated and the effect on 


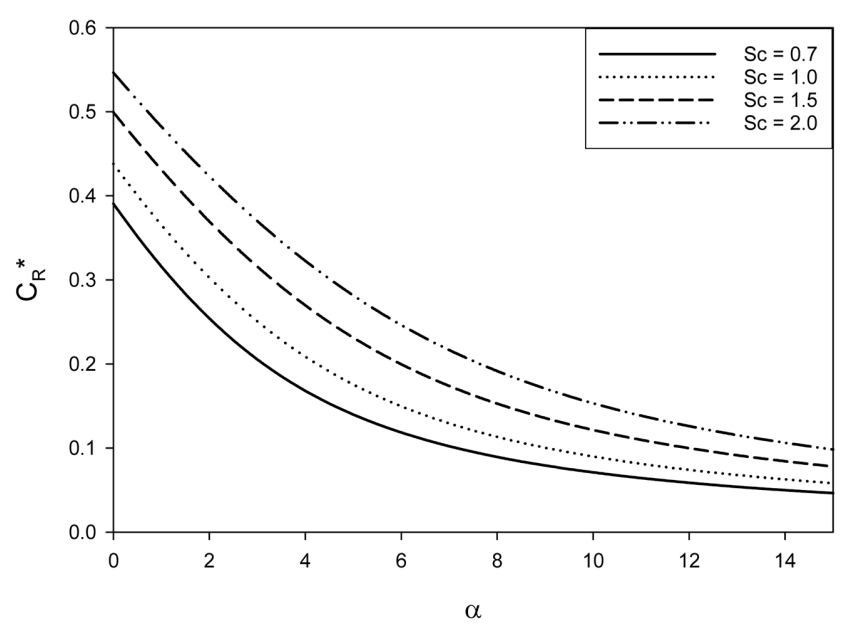

Fig. 5. The effect of the Schmidt number on the concentration of species $A$ at fluid-membrane interface vs. the maximum facilitation factor $\left(\beta=5.0, \mathrm{Vy}^{*}=-0.4,\left(\mathrm{St}_{\mathrm{m}} \mathrm{H} / \mathrm{Sc}\right) \sqrt{\operatorname{Re}_{x}}=1.0\right)$.

facilitation is small. The higher the concentration the more the reversible reaction shifts to the left and becomes saturated. When $\beta=0$, the equilibrium facilitation factor is maximum and the most efficient separation occurs as shown in Fig. 3.

The effect of the Schmidt number, Sc, on the concentration of species $A$ at the fluid-membrane interface $C_{R}^{*}$ is shown in Fig. 5. The smaller the $\mathrm{Sc}$ is, the lower the $\mathrm{C}_{R}^{*}$ will be. $\mathrm{C}_{R}^{*}$ decreases as the value of $\alpha$ increases, which means that the facilitation transfer increases for the increase of the value of $\alpha$, and the more mass transfer effects are affected. It can be also found that the equilibrium facilitation factor increases with the maximum facilitation factor for all the Schmidt numbers.

The effect of dimensionless equilibrium constant $\beta$ on the ratio of the concentration boundary layer thickness to the momentum boundary layer thickness $\delta_{c} / \delta$ vs. the maximum facilitation factor $\alpha$ is given in Fig. 6 . The effect of the dimensionless equilibrium constant is opposite to that of the maximum facilitation factor. The

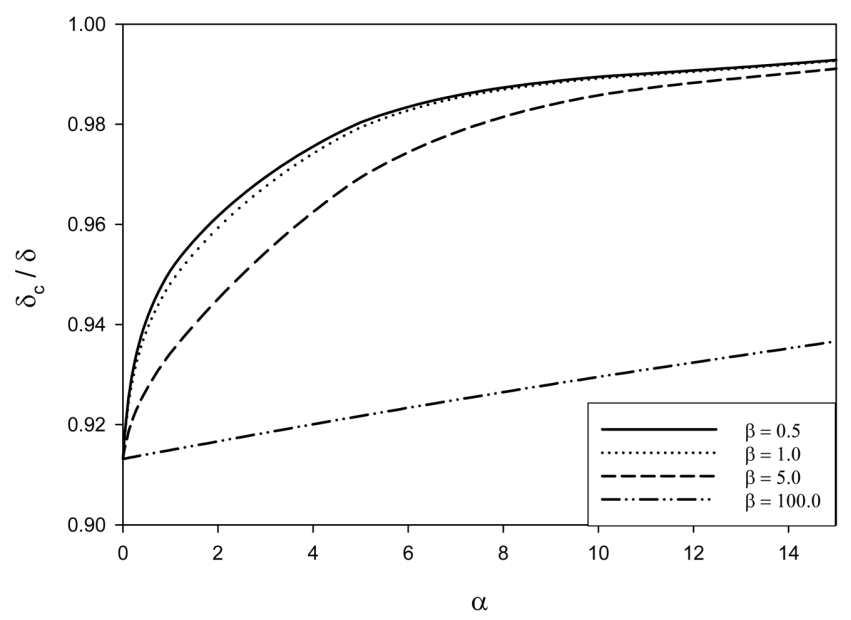

Fig. 6. The effect of the dimensionless equilibrium constant on the ratio of concentration boundary layer thickness to the momentum boundary layer thickness vs. the maximum facilitation factor $\left(\mathrm{Sc}=1.0, \mathrm{Vy}^{*}=-0.4, \mathrm{St}_{m} \mathrm{H}\left(\mathrm{Re}_{x}^{1 / 2}\right) / \mathrm{Sc}=1.0\right)$.

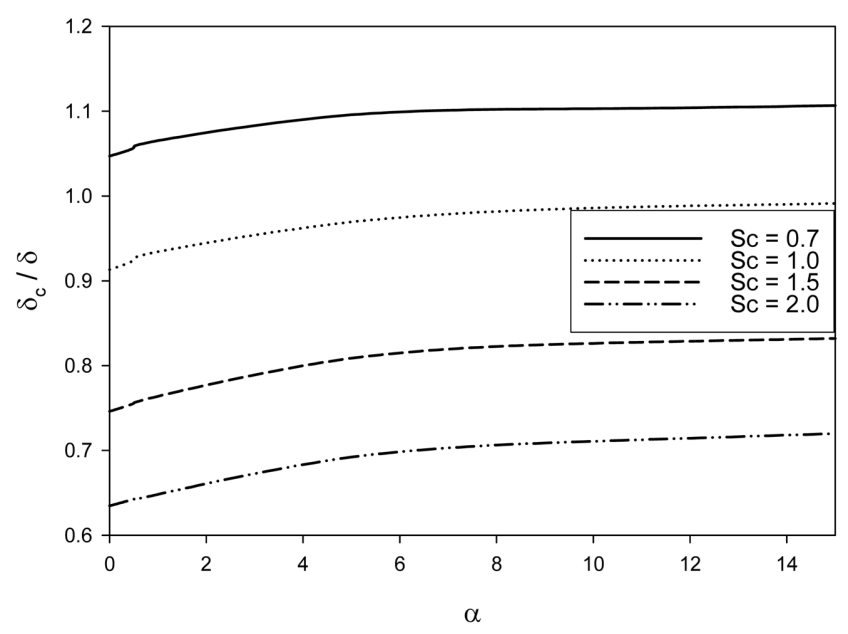

Fig. 7. The effect of Schmidt number on the ratio of concentration boundary layer thickness to the momentum boundary layer thickness vs. the maximum facilitation factor $(\beta=5.0$, $\left.\mathrm{Vy}^{*}=-0.4,\left(\mathrm{St}_{\mathrm{m}} \mathrm{H} / \mathrm{Sc}\right) \sqrt{\mathrm{Re}_{x}}=1.0\right)$.

dimensionless equilibrium constant gives a measure of the strength of the complexation reaction of the transported species with carrier species [Kim and Stroeve, 1988]. From Figs. 3 and 6, both $\mathrm{F}_{e q}$ and $\delta_{c} / \delta$ increase as the value of the maximum facilitation factor $\alpha$ increases. This means the ratio of the concentration boundary layer to the momentum boundary thickness is increased as the facilitated transport proceeds. Fig. 3 also shows that when $\beta$ is equal zero, $\mathrm{F}_{e q}$ approaches the expected value as calculated by Eq. (20).

Fig. 7 shows the effect of Schmidt number on the ratio of concentration boundary layer thickness to the momentum boundary layer thickness $\delta_{c} / \delta$. From boundary layer theory [Schlichting and Gersten, 2000], for $\mathrm{Sc}=1$, the value $\delta_{c} / \delta$ is one, but in the figure it is not one for the smaller value of the maximum facilitation factor $\alpha$, and it will approach the value one for $\alpha$ increasing. The main reason is due to facilitation mass transfer: it is similar to the case for increasing of the suction velocity, and the boundary layer of mo-

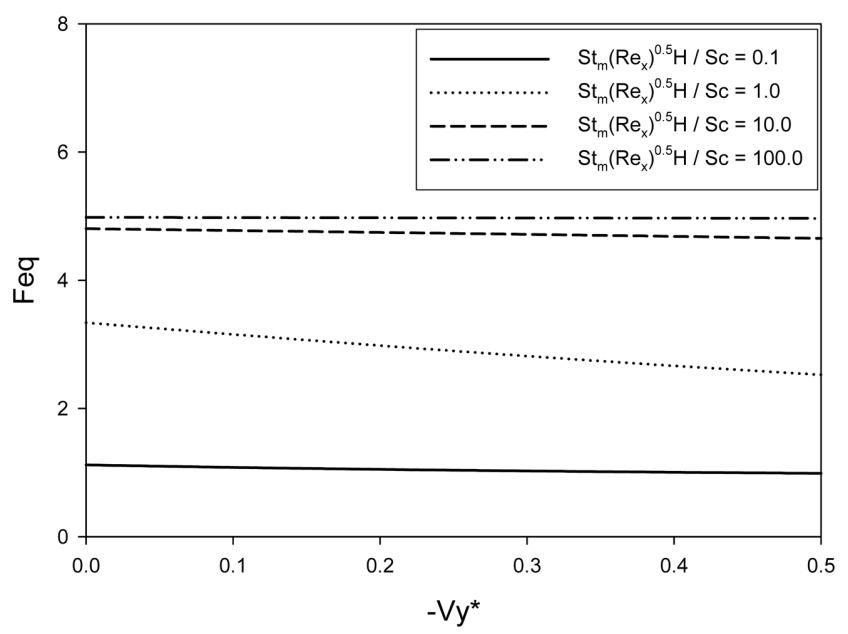

Fig. 8. The effect of the similarity transformation parameter on the equilibrium facilitation factor vs. dimensionless velocity $(\alpha=5.0, \beta=5.0, \mathrm{Sc}=1.0)$. 
mentum transfer and mass transfer becomes very thin [Schlichting and Gersten, 2000]; finally the value $\delta_{c} / \delta$ becomes one for the case of a Schmidt number of one.

The effect of similarity transformation parameter $\mathrm{St}_{m} \mathrm{H}\left(\mathrm{Re}_{x}^{1 / 2}\right) / \mathrm{Sc}$ on equilibrium facilitation factor $\mathrm{F}_{e q}$ vs. dimensionless velocity $-\mathrm{V}_{y}^{*}$ is given in Fig. 8. The similarity transformation parameter is proportional to the mass transfer. The $\mathrm{St}_{m} \mathrm{H}\left(\mathrm{Re}_{x}^{1 / 2}\right) / \mathrm{Sc}$ value means good mass transfer in the membrane. The dimensionless velocity is given as a measure of the suction velocity of the fluid. The parameter can be used to adjust the permeable rate of fluid. The large $-\mathrm{V}_{y}^{*}$ increases the membrane-fluid interfacial concentration of the carrier-complex species to make the facilitated transport decrease, but the effect is not evident. When the $-\mathrm{V}_{y}^{*}$ increased, the equilibrium facilitation factor decreased slowly. The high similarity transformation parameter gives high equilibrium facilitation factor, although the effect of $-\mathrm{V}_{y}^{*}$ is not so obvious.

The effect of similarity transformation parameter $\mathrm{St}_{m} \mathrm{H}\left(\mathrm{Re}_{x}^{1 / 2}\right) / \mathrm{Sc}$

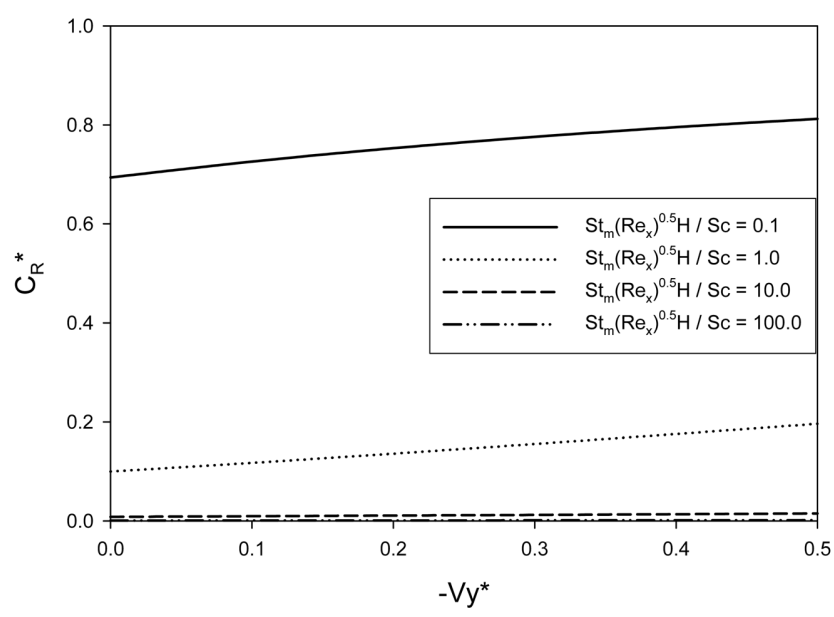

Fig. 9. The effect of the similarity transformation parameter on the dimensionless concentration of species $A$ at fluid-membrane interface vs. the dimensionless velocity $(\alpha=5.0, \beta=5.0$, $\mathrm{Sc}=1.0)$.

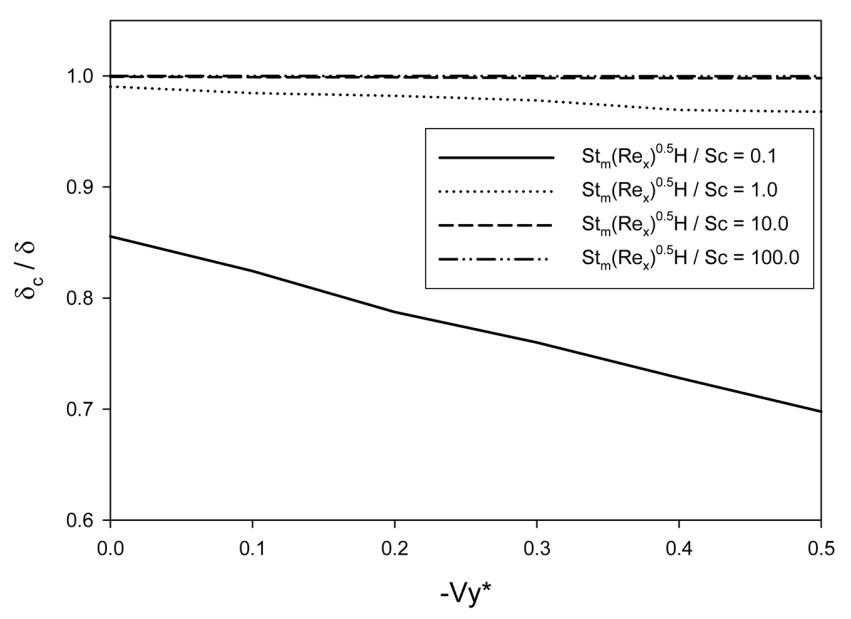

Fig. 10. The effect of the similarity transformation parameter on the ratio of the concentration boundary layer thickness to the momentum boundary layer thickness vs. the dimensionless velocity $(\alpha=5.0, \beta=5.0, \mathrm{Sc}=1.0)$. on the membrane-fluid interfacial concentration $\mathrm{C}_{R}^{*}$ vs. dimensionless velocity $-\mathrm{V}_{y}^{*}$ is shown in Fig. 9. The higher the value of $-\mathrm{V}_{y}^{*}$, the lower membrane-interfacial concentration will be, but the effect is not evident as in the previous discussion. When the $\mathrm{St}_{m} \mathrm{H}\left(\mathrm{Re}_{x}^{1 / 2}\right) /$ Sc increases, the membrane-fluid interfacial concentration decreases quickly to nearly a constant low value. The high similarity transformation parameter gives a low membrane-fluid interfacial concentration; thus it results in the high equilibrium facilitation factor.

Fig. 10 shows the effect of similarity transformation parameter $\mathrm{St}_{m} \mathrm{H}\left(\mathrm{Re}_{x}^{1 / 2}\right) / \mathrm{Sc}$ on the ratio of the concentration boundary layer thickness to the momentum boundary layer thickness $\delta_{\mathrm{c}} / \delta$ vs. dimensionless velocity $-\mathrm{V}_{y}^{*}$. For a similarity transformation parameter less than one, the higher the value of $-\mathrm{V}_{y}^{*}$ is the lower the ratio of the concentration boundary layer thickness to the momentum boundary layer thickness will be. The ratio of the concentration boundary layer thickness to the momentum boundary layer thickness is nearly equal to one as the value of $\mathrm{St}_{m} \mathrm{H}\left(\mathrm{Re}_{x}^{1 / 2}\right) / \mathrm{Sc}$ greater than ten, because a high $\mathrm{St}_{m} \mathrm{H}\left(\mathrm{Re}_{x}^{1 / 2}\right) / \mathrm{Sc}$ value means high permeability of the solute materials.

\section{CONCLUSION}

The maximum facilitation factor, dimensionless equilibrium constant, dimensionless velocity, and similarity transformation parameter can have a significant effect on the mass transfer of laminar flow in single-membrane mass separation devices with Damköhler number equal to infinity. For a reactive membrane, the equilibrium facilitation factor, interfacial concentration and the ratio of concentration boundary layer thickness to momentum boundary layer thickness are a function of maximum facilitation factor, dimensionless equilibrium constant, dimensionless velocity, and similarity transformation parameter. In general, increasing the maximum facilitation factor and similarity transformation parameter will increase the value of the equilibrium facilitation factor and the ratio of the concentration boundary layer thickness to the momentum boundary layer thickness, and decrease the interfacial concentration. However, the dimensionless equilibrium constant and the dimensionless velocity have the reverse effect on the value of the equilibrium facilitation factor, interfacial concentration and the ratio of the concentration boundary layer thickness to the momentum boundary layer thickness.

\section{NOMENCLATURE}

$\mathrm{C}_{A 1} \quad$ : concentration of solute species A in zone $1\left[\mathrm{~mol} \mathrm{~m}^{-3}\right]$

$\mathrm{C}_{B}$ : concentration of carrier species B $\left[\mathrm{mol} \mathrm{m}^{-3}\right]$

$\mathrm{C}_{1}^{*} \quad$ : dimensionless concentration of species $\mathrm{A}$ in Zone $1=$ $\mathrm{C}_{A 1} / \mathrm{C}_{A i}$

$\mathrm{C}_{A i} \quad$ : inlet concentration of species $\mathrm{A}\left[\mathrm{mol} \mathrm{m}^{-3}\right]$

$\mathrm{C}_{m} \quad$ : mixing cup concentration $\left[\mathrm{mol} \mathrm{m}^{-3}\right]$

$\mathrm{C}_{m}^{*} \quad$ : dimensionless mixing cup concentration $=\mathrm{C}_{m} / \mathrm{C}_{A i}$

$\mathrm{C}_{R}^{*} \quad$ : dimensionless concentration of species $\mathrm{A}$ at interface of fluid-membrane $\left[\mathrm{mol} \mathrm{m}^{-3}=\mathrm{C}_{A 1(y=0)} / \mathrm{C}_{A i}\right]$

$\mathrm{C}_{T}$ : total concentration of carrier species in all forms (B and $\mathrm{C}$ ) $\left[\mathrm{mol} \mathrm{m}^{-3}\right]$

$\mathrm{D}_{A} \quad$ : diffusivity of $\mathrm{A}$ in fluid $\left[\mathrm{m}^{2} \mathrm{~s}^{-1}\right]$

$\mathrm{D}_{A}^{\prime} \quad$ : effective diffusivity of $\mathrm{A}$ in reactive membrane $\left[\mathrm{m}^{2} \mathrm{~s}^{-1}\right]$ 
$\mathrm{D}_{B}^{\prime} \quad$ : effective diffusivity of $\mathrm{B}$ in reactive membrane $\left[\mathrm{m}^{2} \mathrm{~s}^{-1}\right]$

f $\quad$ : dimensionless stream function $=\left(\mu \mathrm{U}_{\infty} \mathrm{x} / \rho\right)^{-1 / 2} \psi$

$\mathrm{F}_{e q} \quad$ : equilibrium facilitation factor

$\mathrm{H}$ : equilibrium distribution coefficient of solute concentration in the membrane to the concentration in the fluid

$\mathrm{k}_{1} \quad$ : forward rate constant $\left[\mathrm{m}^{3} \mathrm{~mol}^{-1} \mathrm{~s}^{-1}\right]$

$\mathrm{k}_{2} \quad$ : backward rate constant $\left[\mathrm{s}^{-1}\right]$

$\mathrm{K}_{e q}$ : equilibrium constant for the chemical reaction $=\mathrm{k}_{1} / \mathrm{k}_{2}\left[\mathrm{~m}^{3}\right.$ $\left.\mathrm{mol}^{-1}\right]$

$\mathrm{k}_{w} \quad$ : membrane mass transfer coefficient $=\mathrm{D}_{\mathrm{A}}^{\prime} / \mathrm{L}\left[\mathrm{m} \mathrm{s}^{-1}\right]$

$\mathrm{L} \quad$ : thickness of membrane [m]

$\operatorname{Re}_{x}:$ Reynolds number $=\rho \mathrm{U}_{\infty} \mathrm{X} / \mu$

$\mathrm{St}_{m} \quad$ : Stanton number of mass transfer $=\mathrm{k}_{w} / \mathrm{U}_{\infty}$

$\mathrm{Sc} \quad$ : Schmidt number $=v / \mathrm{D}_{A}$

$\mathrm{u}_{w} \quad$ : $\mathrm{y}$-direction velocity on the membrane surface $\left[\mathrm{m} \mathrm{s}^{-1}\right]$

$\mathrm{u}_{x} \quad: \mathrm{x}$-direction velocity $\left[\mathrm{m} \mathrm{s}^{-1}\right]$

$\mathrm{u}_{y} \quad$ : y-direction velocity $\left[\mathrm{m} \mathrm{s}^{-1}\right]$

$\mathrm{U}_{\infty} \quad$ : inlet velocity $\left[\mathrm{m} \mathrm{s}^{-1}\right]$

$\mathrm{Vy}^{*}:$ dimensionless velocity $=\mathrm{u}_{w}\left(\mathrm{Re}_{x}\right)^{1 / 2} / \mathrm{U}_{\infty}$

$\mathrm{x} \quad$ : coordinate

y : coordinate

\section{Greek Letters}

$\alpha \quad:$ maximum facilitation factor $=\mathrm{D}_{B}^{\prime} \mathrm{C}_{T} \mathrm{~K}_{e q} / \mathrm{D}_{A}^{\prime}$

$\beta \quad$ : dimensionless equilibrium constant $=\mathrm{K}_{e q} \mathrm{HC}_{A i}$

$\delta \quad:$ momentum boundary layer thickness [m]

$\delta_{c} \quad$ : concentration boundary layer thickness [m]

$\eta \quad$ : dimensionless similarity variable $=\mathrm{y}\left(\mathrm{U}_{\infty} / 4 v \mathrm{x}\right)^{1 / 2}$

$\mu \quad$ : viscosity of fluid [Pa s]

$v \quad:$ kinematic viscosity $=\mu / \rho\left[\mathrm{m}^{2} \mathrm{~s}^{-1}\right]$

$\rho \quad:$ density of fluid $\left[\mathrm{kg} \mathrm{m}^{-3}\right]$

$\psi \quad:$ stream function $\left[\mathrm{m}^{2} \mathrm{~s}^{-1}\right]$

\section{REFERENCES}

Cussler, E. L., Diffusion, chap.15, Cambridge University Press, London GB (1986).

Hartnett, J. P. and Eckert, E. R. G, "Mass transfer cooling in a laminar boundary layer with constant properties," Trans. Am. Soc. Mech. Eng., 79, 247 (1957).

Kim, J. I. and Stroeve, P., "Mass transfer in separation devices with reactive hollow fiber,' Chem. Eng. Sci., 43, 247 (1988).

Kreuzer, F. and Hoofd, L. J. C., Facilitated diffusion of oxygen and carbon dioxide, in "Handbook of physiology-respiration" (edited by Fahri, L. E. and Tenney, S. M.), 4, pp. 89-111, American Physiological Socieity, Bethesda, Maryland, USA (1987).

La force, R. C., "Steady-state diffusion in carbon monoxide oxygen haemoglobin system,' Trans. Faraday. Soc., 62, 1458 (1966).

Leu, L. P., Lin, C. C. and Stroeve, P., "Mass transfer in parallel-plate separation devices with nonequilibrium facilitated reactive membranes,' Trans. I. Chem. Eng., Part A, 74, 701 (1996).

Leu, L. P. and Stroeve, P., "Mass transfer in separation devices with reactive hollow fibre," Proc. Sixth Conf. of the Asian Pacific Confederation of Chemical Engineering, Melbourne, Australia, 3, 381 (1993).

Noble, R. D., "Shape factors in facilitated transport through membranes," Ind. Eng. Chem. Fundam., 22, 139 (1983).

Noble, R. D. and Way, J. D., “Application of liquid membrane technology,' ACS Symp. Ser., 347, 110 (1987).

Scott, J., Membrane and Ultrafiltration Technology, Noyes Data Corporation, Park Ridge, U.S.A. (1980).

Schlichting, H. and Gersten, K., Boundary Layer Theory, $8^{\text {th }}$ Revised and Enlarged edition, chap. 6, 9 and 11, Springer, Singapore (2000).

Schneider, P. J., "Effect of axial fluid conduction on heat transfer in the entrance regions of parallel plates and tubes," Trans. Am. Soc. Mech. Eng., 79, 765 (1957).

Schultz, J. S., Goddard, J. D. and Suchdeo, S. R., "Facilitated transport via carrier-mediated diffusion in membranes. I. Mechanistic aspects, experimental systems and characteristic regimes,' AIChE J., 20, 417 (1974).

Stroeve, P., Smith, K. A. and Colton, C. K., “An analysis of carrier facilitated transport in heterogeneous media," AIChE J., 22, 1125 (1976).

Stroeve, P. and Kim, J. I., "Separation in mass exchange devices with reactive membrane," ACS, Symp. Ser., 347, 39 (1987).

Ward, W. J., III, “Analytical and experimental studies of facilitated transport”, AIChE J., 16, 405 (1970). 